\title{
The Powder Diffraction journal in 2001 and beyond
}

Since its first publication in 1986, the Powder Diffraction (PD) journal has published more than 700 technical and new diffraction data articles contributed by X-ray and materials scientists from all over the world. This past March, the journal editors and members of the Board of Directors of the International Centre for Diffraction Data (ICDD) met at the ICDD annual meeting and reviewed past journal activities, discussed its present status, and developed future plans to improve the quality of the journal and its services to the scientific community. A summary of the topics discussed at the meetings is as follows.

\section{Powder Diffraction online}

The journal has joined AIP's Online Journal Service, and the March issue of Powder Diffraction (Volume 16, Number 1) is the first issue of the journal which can be accessed online. PD online subscribers can browse and search all issues from March 2001 to present. Advanced abstracts, content pages of all past issues from Volume 1 to present, etc., are also accessible. Nonsubscribers to the online version of Powder Diffraction will be able to view the contents of the current issue and some of the past issues. This includes the Table of Contents and the abstracts. A nonsubscriber can also order articles even though they are not able to view the PDF files or HTML files. A subscriber to the online journal can view the entire article.

\section{New cover}

Starting with the June 2001 issue, Powder Diffraction goes to topical cover. Authors are encouraged to submit quality photos or graphs that catch the reader's eyes. Journal editors will also solicit possible photos/graphs from articles to be published in the same issue.

\section{Editorial staff}

To improve the efficiency and speed of the editorial process, PD geometrical editors (namely, Western European Editor: Dr. Norberto Masciocchi, Eastern European Editor: Dr. Jaroslav Fiala, Editor for Southeast Asia: Professor Brian H. O'Connor, and Editor for Japan: Professor Hideo Toraya) have been renamed as editors. Authors can now submit technical articles to the editors of their choice. As in the past, new diffraction data articles should be submitted to the Editor of New Diffraction Data, Professor William Mayo, and review articles to the Editor for Reviews and Reprints, Professor Deane K. Smith.

In view of an increase in the contributions and submissions from authors in the Central and South Americas, we are delighted to announce that Professor José Miguel Delgado of Venezuela has agreed to serve as an editor for PD. Professor Delgado is a faculty member of the Chemistry De- partment of Universidad de Los Andes (ULA) in Mérida, Venezuela. He obtained his Ph.D. degree in materials science from the Department of Materials Science and Engineering at Massachusetts Institute of Technology (MIT) in 1988. He has been the head of the Crystallography Laboratory at ULA, Chairman of the Chemistry Graduate Committee, a member of the Technical Committee for South America of ICDD, and a member of the Steering Committee of the International $\mathrm{X}$-Ray Analysis Society. Professor Delgado has been actively promoting the use of $\mathrm{X}$-ray diffraction techniques in South America by organizing fundamentals and specialized workshops and schools in the region. He has over fifty publications in international refereed journals, several invited lectures and numerous presentations in national and international scientific meetings. He is a member of the Venezuelan Association for the Advancement of Science (AsoVAC), the American Crystallographic Association (ACA), the Materials Research Society (MRS), and the American Chemical Society (ACS). Currently, he is the Director of the Laboratorio Nacional de Difracción de Rayos-X (LNDRX) financed by the Venezuelan government (CONICIT) as part of the Program of National Laboratories. The addition of Dr. Delgado to our editorial staff will greatly enhance our services to the scientific community in Central and South Americas. Authors from the region are welcome to submit their manuscripts to Dr. Delgado (the addresses of all PD Editors are listed in the masthead).

\section{Editorial Advisory Board}

The journal was fortunate to have the services of an excellent Editorial Advisory Board for the past 15 years. The Board consisted of prominent members from X-ray and materials science communities, and this helped to acquaint the scientific community with the journal. The Board has completed its original missions and was dispensed. We sincerely thank all board members for a job well done.

\section{International reports}

In the past, we had five regional correspondents (namely, Tony Raftery in Australia, Ludwik Gorski in Eastern Europe, Norberto Masciocchi in Western Europe, Hideo Toraya in Japan, and José Migual Delgado in Central and South Americas) who wrote reports on regional activities of interest to X-ray and related communities for the International Reports section of the journal. The regional correspondents serviced the journal well and have now completed their services to the journal. We want to take this opportunity to thank them for their outstanding services. Future contributions for the International Reports section should be submitted directly to the Editor for International Reports, Dr. Winnie Wong-Ng at NIST. 


\section{Journal improvements}

In a continuous effort to improve the quality of the journal, we solicit suggestions for possible lead and review articles. Those articles on popular subjects which may lead to high citation indices will have priority. Suggestions for lead articles should be forwarded to the Editor-in-Chief and for review articles to the Editor for Reviews and Reprints.

It is the responsibility of both journal staff and readers to keep the journal alive and vibrant. Three possible ways to help the journal are:
(1) submitting and encouraging others to submit their best papers to Powder Diffraction,

(2) including in our publications any relevant citations to papers from Powder Diffraction,

(3) convincing our libraries and colleagues to subscribe or to maintain subscriptions.
Ting C. Huang Editor-in-Chief 